\title{
Epistemological dimensions on screen: The role of television presentations in changing conceptions about the nature of knowledge and knowing
}

Guenther, Lars ; Kessler, Sabrina Heike

\begin{abstract}
In (in)formal learning scenarios, individuals should develop epistemological beliefs (i.e., individual conceptions about the nature of knowledge and knowing) that are advantageous for understanding everyday scienceand health-related information. To date, researchers measuring how to foster students' discipline-specific epistemological beliefs have often tested researcher-designed texts in short-term interventions. Applying this logic to audio-visual stimuli, television clips might also affect (e.g., change) the epistemological beliefs of students. To test this assumption, three different television stimuli on the subject of Alzheimer's disease with varying levels depicting the presented knowledge (as more advantageous, moderate, or less advantageous) were therefore selected by means of a content analysis, and their effects tested on a sample of 72 students using a pre-/post-test questionnaire. The results showed some partial support for the assumption that the epistemological beliefs of participants could become less advantageous when they are exposed to television clips depicting knowledge as moderate or less advantageous.
\end{abstract}

DOI: https://doi.org/10.1515/commun-2017-0020

Posted at the Zurich Open Repository and Archive, University of Zurich

ZORA URL: https://doi.org/10.5167/uzh-148323

Journal Article

Published Version

Originally published at:

Guenther, Lars; Kessler, Sabrina Heike (2017). Epistemological dimensions on screen: The role of television presentations in changing conceptions about the nature of knowledge and knowing. Communications : European Journal of Communication Research, 42(4):481-501.

DOI: https://doi.org/10.1515/commun-2017-0020 


\title{
Lars Guenther* and Sabrina H. Kessler Epistemological dimensions on screen: The role of television presentations in changing conceptions about the nature of knowledge and knowing
}

https://doi.org/10.1515/commun-2017-0020

\begin{abstract}
In (in)formal learning scenarios, individuals should develop epistemological beliefs (i.e., individual conceptions about the nature of knowledge and knowing) that are advantageous for understanding everyday science- and health-related information. To date, researchers measuring how to foster students' discipline-specific epistemological beliefs have often tested researcherdesigned texts in short-term interventions. Applying this logic to audio-visual stimuli, television clips might also affect (e.g., change) the epistemological beliefs of students. To test this assumption, three different television stimuli on the subject of Alzheimer's disease with varying levels depicting the presented knowledge (as more advantageous, moderate, or less advantageous) were therefore selected by means of a content analysis, and their effects tested on a sample of 72 students using a pre-/post-test questionnaire. The results showed some partial support for the assumption that the epistemological beliefs of participants could become less advantageous when they are exposed to television clips depicting knowledge as moderate or less advantageous.
\end{abstract}

Keywords: epistemological beliefs, television clips in (in)formal learning environments, science and health communication

\footnotetext{
Note: Both authors contributed equally to this work. We wish to thank our anonymous reviewers for their helpful comments. We would also like to thank Antje Blumstengel, Franziska Dau, Anja Dittrich, David Hildebrandt, Magdalena Rosset, Lisa Marie Schaaf, and Philip Thomisch for developing our research within a master's course at Friedrich Schiller University, Jena, Germany; we also thank Julia L. McMillan, Jackie Viljoen, and Julia Fränzel for proofreading manuscripts.
}

*Corresponding author: Lars Guenther, Centre for Research on Evaluation, Science and Technology (CREST), Stellenbosch University, Stellenbosch, South Africa, E-mail: larsguenther@sun.ac.za

Sabrina H. Kessler, Institute of Communication Research, Friedrich Schiller University, Jena, Germany, E-mail: sabrina.kessler@uni-jena.de 


\section{Introduction}

It is often believed that students need, among other things, more advantageous epistemological beliefs to better understand everyday science and health-related information (Bromme and Kienhues, 2014; Conley, Pintrich, Vekiri, and Harrison, 2004). ${ }^{1}$ Epistemological beliefs are individual theories and conceptions about the nature of knowledge and knowing (Hofer, 2001; Urhahne and Hopf, 2004), and are divided by some authors into the four dimensions certainty of knowledge, simplicity of knowledge, source(s) of knowledge, and justification for knowing (Hofer and Pintrich, 1997; see theoretical chapter). ${ }^{2}$ Epistemological beliefs are an important field to study. Fostering more advantageous epistemological beliefs is perceived as an educational goal (Conley et al., 2004; Sinatra, Kienhues, and Hofer, 2014; Urhahne and Hopf, 2004). In addition, modern societies make copious use of the advanced literacy and reasoning skills of their individuals (Ashe, 2013). As more and more (and sometimes diverging) information becomes accessible (in a knowledge-based society), individuals have to be careful when making judgments, when deciding which source(s) to trust, and when evaluating the given evidence of (scientific) claims (Bråten et al., 2011;

1 In this article, we refer to epistemological beliefs as more advantageous (when people predominantly believe that knowledge is changing, uncertain, and a well-reasoned outcome, which is at the same time perceived to help them understand, handle new information, and make better and knowledge-based decisions) or less advantageous (when people believe that knowledge is more stable and certain) (see also Kienhues, Ferguson, and Stahl, 2016). While research in this field commonly uses the terms "sophisticated" and "naïve" (Conley et al., 2004; Kienhues, Bromme, and Stahl, 2008; Wegner, Weber, and Fischer, 2012) to describe the range/continuum of epistemological beliefs, we believe that using the terms "less advantageous" and "more advantageous" is to some degree less value-laden (see also Kienhues, Stadtler, and Bromme [2011], who used "less advanced" or "more advanced", or Bråten, Britt, Strømsø, and Rouet [2011]; however, despite this change in terminology, we refer to the same approach that has been used by other researchers.

2 There are, however, different paradigmatic approaches to research in this field (e.g., Bråten et al., 2011), as well as different terms to describe beliefs about the nature of knowledge and knowing. "Epistemological beliefs" is, however, the most widely used term (see also Kienhues et al., 2008). The most accepted definition of epistemological beliefs is that proposed by Hofer and Pintrich (1997), which is an extension and reformulation of different research approaches, such as Schommer's (1990) five epistemological dimensions (see also Conley et al., 2004). It should be added that recently, Kienhues et al. (2016) rather referred to "epistemic cognition" (see also Chinn, Buckland, and Samarapungavan [2011], who extended the framework used by Hofer and Pintrich [1997], as well as Schommer-Aikins [2004] and Muis and Duffy [2013], who introduced notions on the epistemic climate). With respect to Sinatra et al. (2014), epistemic cognition includes both epistemological beliefs and the application and/or influence of these beliefs on everyday problems. 
Kienhues et al., 2016; Sinatra et al., 2014). Advantageous epistemological beliefs are then believed to increase understanding and to help people make better decisions (see also Kienhues et al., 2011).

As a result, researchers design studies to foster more advantageous epistemological beliefs among individuals. For instance, some researchers who are interested in epistemological change use researcher-designed texts as stimuli in short-term interventions (Gill, Ashton, and Algina, 2004; Kienhues et al., 2008). Applying this logic to real and audio-visual stimuli is relevant, since television (TV) is currently among the most important and often the only source that individuals use to inform themselves about science and health issues, and this is especially true for a German audience (European Commission, 2013). Watching TV programs and clips about science provides, to some degree, an informal learning environment, as people watch these programs to be entertained and informed, and learn from this (Kessler and Guenther, 2013; Kessler, Guenther, and Ruhrmann, 2014; Lehmkuhl et al., 2012; Milde, 2009). In addition, TV clips about diverse issues are also part of formal learning scenarios, for instance, health and science-related clips used in biology classes (for teachers' use of information and communications technology, see Mumtaz, 2006). If the reception of such TV clips at home, at school, or university is conceptualized as (in)formal learning scenarios, the clips may also be able to transmit and change epistemological beliefs among students (Kessler and Guenther, 2013). This claim was tested in the study on which the present article is based.

In this article, three real-world and therefore authentic TV clips about Alzheimer's disease (identified through a systematic content analysis [Kessler and Guenther, 2013; Kessler et al., 2014]) depicting different levels of knowledge representation (as more advantageous, moderate advantageous, or less advantageous) were tested in a pre-/post-experiment set-up. Students' epistemological beliefs were measured before and after stimuli exposure to obtain a detailed understanding of possible changes in beliefs in response to exposure to a TV clip.

\section{Theoretical review: Research on epistemological beliefs}

Epistemological beliefs are often defined as "an identifiable set of dimensions of beliefs about knowledge and knowing, organized as theories, progressing in reasonably predictable directions, activated in context, operating both cognitively and metacognitively" (Hofer, 2010, p. 98). Epistemological beliefs are 
being given more and more attention by researchers in both psychology and educational research (Conley et al., 2004; Kienhues et al., 2008, 2011; Sinatra et al., 2014; Wegner et al., 2012), but not yet so much in communication research. As an intuitive or naïve theory of science (Bromme and Kienhues, 2014), epistemological beliefs can provide a basic orientation towards scientific information (Sinatra et al., 2014). Epistemological beliefs influence, for instance:

- how adolescents and students comprehend and learn information (Hofer and Pintrich, 1997; Wegner et al., 2012);

- how they integrate new knowledge into their existing knowledge base (Jacobson and Spiro, 1995);

- how different information from multiple sources is integrated into an individual's coherent knowledge representation (Bråten et al., 2011; Ferguson, Bråten, and Strømsø, 2012); and

- how people deal with contradictions and evaluate scientific evidence (Sinatra et al., 2014).

Hofer and Pintrich (1997) classify epistemological beliefs on the basis of four contiguous, empirically supported dimensions, identified across several models and defined as the core of many investigations (Hofer, 2001, 2004a; Hofer and Pintrich, 1997). The first two dimensions represent the nature of knowledge (i.e., what one believes knowledge is); the last two represent the nature or the process of knowing (i.e., how one acquires knowledge) (Hofer and Pintrich, 1997), with each of the dimensions reflecting a continuum from less advantageous to more advantageous (Hofer, 2004a). The first dimension is certainty of knowledge - its perceived stability and certainty, compared to its uncertainty and tentativeness (Conley et al., 2004). The tentativeness of science is one of the foundations of scientific work (Popper, 1960; Sinatra et al., 2014). This dimension represents the degree to which knowledge is seen as fixed and absolutely true or, in contrast, as temporary, growing, changing, and evolving. The second dimension, simplicity of knowledge, refers to the continuum from a simple accumulation of facts to interrelated and potentially contradictory knowledge. The third dimension refers to source(s) of knowledge. Knowledge can be acquired from a single external source like an expert (e.g., a spokesperson) or authority, or knowledge can be internally protected by the juxtaposition of multiple sources, such as research studies and scientific experts (Kessler et al., 2014). The fourth dimension, justification for knowing, concerns the fact that knowledge can be justified either scientifically or non-scientifically; accordingly, this dimension explores the way information or data is weighted (Hofer and Pintrich, 1997). All four dimensions are relevant to an individual's understanding of science (Sinatra et al., 2014). 
Many researchers have tried to identify factors that can foster more advantageous epistemological beliefs among students and others. In this article and regarding the argumentation to this point, we follow disparate models from an educational psychology perspective (Kienhues et al., 2008; Kienhues et al., 2016). ${ }^{3}$ Within this perspective, epistemological beliefs are perceived as multidimensional and interrelated (Hofer, 2004b). It is further believed that individuals can simultaneously hold both more advantageous and less advantageous views for different dimensions of epistemological beliefs (Kienhues et al., 2008; Schommer, 1990; Schommer-Aikins, 2004), and that individuals can also hold both general and discipline-specific (or even topic-specific) beliefs about knowledge and knowing (Bråten et al., 2011; Hofer, 2010).

Research in both education and psychology has demonstrated that students' epistemological beliefs are significantly influenced by the mediation styles (e.g., teaching methods) of their lecturers, as well as by how knowledge is represented in teaching materials (Broughton, Sinatra, and Nussbaum, 2013; Lombardi, Sinatra, and Nussbaum, 2013; Muis and Duffy, 2013; see also Hofer, 2004a). TV material, however, was not tested in these investigations. Although researchers agree that epistemological beliefs develop and change over time, the concrete mechanisms of this change have not yet been investigated in full detail.

Conceptual change (i.e., the reorganizing of existing knowledge following new experiences, which can lead to discrepancies) could be one of the underlying mechanisms of changes in epistemological beliefs. See in this regard Dole

3 It should be mentioned that there are also models that follow a more resource-oriented approach (Louca, Elby, Hammer, and Kagey, 2004) or a more developmental approach (Kuhn, Cheney, and Weinstock, 2000; see also Kienhues et al., 2016). Within the developmental approach, it is perceived that individuals change their epistemological beliefs across their life span in a developmental fashion, characterized as a certain way of thinking in which beliefs about different aspects are coherent and related to each other (Conley et al., 2004). As a result, these beliefs will also change over time (see Kienhues et al., 2008). While this begins in early adolescence, it continues into adulthood and is often related to age and educational level (King and Kitchener, 2002; see also Bendixen and Rule, 2004). This developmental (and more long-term) process normally starts with an absolutistic view positing certain, simple, and stable knowledge, moving towards a multiplistic and evaluativistic view in which individuals learn that knowledge is relativistic and uncertain (for an overview, see also Kienhues et al., 2008; Rule and Bendixen, 2010; Schommer-Aikins, 2004). Bendixen and Rule (2004) highlight that both developmental and disparate models can be united because epistemological thinking develops and is multidimensional. With respect to the resource-oriented approach, it is believed that epistemologies are made up of resources for understanding knowledge, which are defined as units of cognitive structure at a finer grain size than beliefs (Louca et al., 2004; see also Greene and Yu, 2014). 
and Sinatra (1998), Gill et al. (2004), Kienhues et al. (2008), Muis and Duffy (2013), and Sinatra et al. (2014) for more information. According to Bendixen and Rule (2004) and their integrated model of personal epistemology, mechanisms of change consist of three interrelated components: epistemic doubt, epistemic volition, and resolution strategies (see also Rule and Bendixen, 2010). Epistemic doubt refers to the questioning of one's beliefs and their validity at any stage of epistemological development (Bendixen and Rule, 2004). Raised, for instance, by receiving diverging information, epistemic doubt is believed to lead to epistemic change. Introducing new and conflicting viewpoints to an issue might trigger cognitive conflict, dissatisfaction, and dissonance in individuals. As a result, individuals' epistemic change might become more likely (Kienhues et al., 2016). Epistemic volition refers to direct effort needed to solve this dissonance (and the responsibility an individual then has to take), while resolution strategies comprise reflection and interaction processes (for more information, see Bråten et al., 2011; Bendixen and Rule, 2004; Rule and Bendixen, 2010; Kienhues et al., 2008). Bendixen and Rule (2004) also highlight that dissonance and personal relevance, among others, are two isolated potential conditions for epistemological change (see also Dole and Sinatra, 1998), while others emphasize the role of emotions (Broughton et al., 2013) or plausibility (Lombardi et al., 2013) when it comes to conceptual change (see also Rule and Bendixen, 2010).

One stream of research that is interested in fostering epistemic change is related to short-term interventions ${ }^{4}$ and direct exposure to conflicting knowledge in a (researcher-designed) text (Kienhues et al., 2016). For research on multiple texts, see, for instance, Ferguson et al. (2012). ${ }^{5}$ Research in this field is probably the most similar to watching short TV clips in (in)formal learning environments. That is why we wanted to review literature in this field in more detail.

Gill et al. (2004) conducted an investigation into pre-service mathematics teachers and found that those exposed to a refutational text, ${ }^{6}$ which included

4 For a research article observing changes of epistemological beliefs over a longer term, readers are guided to Muis and Duffy (2013).

5 According to Kienhues et al. (2016, p. 323), a second set of instructional intervention studies to foster epistemic change focuses on "experiences within constructivist, hands-on science courses” (see also Conley et al., 2004).

6 Refutation texts are those texts that state widely-held assumptions and refute them by presenting a more scientific explanation; thus, these texts are perceived as making individuals question their own beliefs, and are likely to promote conceptual change (Broughton et al. 2013; Gill et al., 2004; Kienhues et al., 2008). 
causal arguments and multiple sources, were more likely to change their epistemological beliefs into more advantageous ones than those teachers exposed to a standard textbook text with more accepted knowledge and less complex epistemology. Kienhues et al. (2008) further noted that students who received a refutational text outlining uncertainties and difficulties were more likely to change their beliefs into more advantageous ones concerning the texture (e.g., the complexity) and variability (e.g., stability) of knowledge in genetics. Students who received informational and one-sided instruction (a textbook passage) were, in turn, more likely to focus on a certain and stable view, even changing their epistemological beliefs towards a less advantageous standpoint. Further results of a study by Kienhues et al. (2011) revealed that different kinds of information (i.e., consistent vs. conflicting representations) about cholesterol evoked different beliefs in students. For instance, participants in the group that was exposed to a text with conflicting claims (= more advantageous representation) were less certain of the ability of experts to come to a decision than were participants in the group that was exposed to consistent claims (= less advantageous representation).

These findings were applied to audio-visual stimuli in the present investigation. Regarding informal learning contexts, TV is the main source of scientific and medical information for the general public (European Commission, 2013), with science TV programs ${ }^{7}$ among the favorite sources for German audiences (Lehmkuhl et al., 2012). Regarding formal learning scenarios, TV clips are part of teaching strategies in several school or university classes. Kessler and Guenther (2013) assumed that clips from science TV programs could foster more or less advantageous epistemological beliefs among audience members, depending on how those clips represent knowledge. In a first study, Kessler and Guenther (2013) investigated a full sample of science and medicine-related TV clips broadcast in German science TV programs. In line with the definition by Hofer and Pintrich (1997), they conducted a content analysis investigating the four epistemological dimensions: certainty of knowledge, simplicity of knowledge, sources of knowledge, and justification for knowing (see also Kessler et al., 2014). The authors found that there are indeed different representations of knowledge in science TV programs. These styles vary in the extent to which they depict the four dimensions (and thus, the represented knowledge) as more advantageous, moderately advantageous, or less advantageous. To date, the effects of these

7 German science TV programs have been developed to inform audiences about diverse science and medicine-related issues. Clips usually last two to three minutes, are presented by a journalist, and are broadcast in the form of multiple TV clips with different thematic scopes within one program (Milde, 2009). 
different representations of knowledge have not yet been investigated. That is why the central research question (RQ) of the present study was:

[RQ] Can medicine- and science-related TV clips that vary in how they depict knowledge (as more advantageous, moderately advantageous, or less advantageous) change students' epistemological beliefs?

Research in education and psychology has indicated that stimuli (albeit almost exclusively researcher-designed texts) can change individual discipline-specific epistemological beliefs in short-term interventions (Gill et al., 2004; Kienhues et al., 2008; Kienhues et al., 2011). Materials depicting knowledge more advantageously tend to encourage more advantageous beliefs by individuals, while materials depicting knowledge less advantageously tend to encourage less advantageous beliefs. That is why we stated the following hypotheses (Hs):

[H1] A science TV clip depicting knowledge more advantageously fosters more advantageous epistemological beliefs among students.

[H2] A science TV clip depicting knowledge less advantageously leads to less advantageous epistemological beliefs among students.

\section{Method}

\subsection{Design, participants, and procedure}

This study was part of a more extensive eye-tracking experiment, in which 72 students participated (Kessler and Guenther, 2017). The students were recruited on the campus of Friedrich Schiller University in Jena, Germany, by randomly inviting people to take part in the study. When the participants arrived at the media laboratory they received a paper-and-pencil pre-survey questionnaire measuring their epistemological beliefs (Time One $=t 1$ ), since surveying was found to be an established technique when investigating epistemological beliefs (Hofer, 2004b). ${ }^{8}$ The important covariates of topic-related involvement,

8 It should be added, however, that there are different methodological approaches when investigating epistemological beliefs and that self-reporting instruments, such as surveys, although being regarded as an established instrument, have been criticized in the research literature (Greene and Yu, 2014). Urhahne and Hopf (2004) highlight that especially those researchers who follow the perception that epistemological beliefs are multidimensional are the ones using survey measurements. 


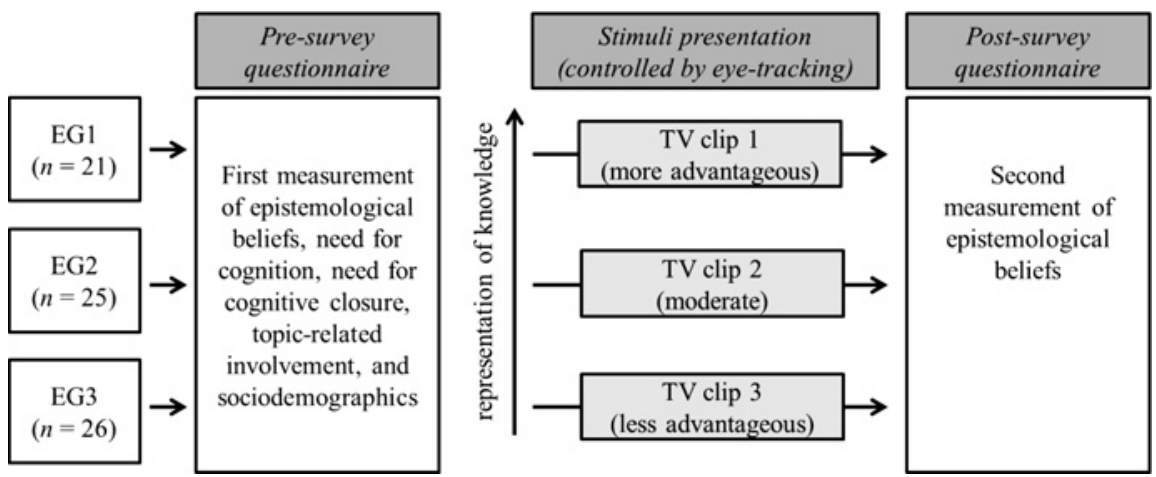

Figure 1: Design of the pre/post-test experiment. Participants watched one of three TV clips about Alzheimer's disease. These clips varied in their level of depicting knowledge, which was assessed based on a content analysis (Kessler and Guenther, 2013; Kessler et al., 2014). $E G$ = experimental group.

need for cognition, need for cognitive closure, and sociodemographics (Kienhues et al., 2008; Sinatra et al., 2014) were measured at t1. Participants were then randomly divided into three experimental groups (EGs), each associated with one of three TV clips that varied in in how they represented knowledge (TV clip 1 = more advantageous representation, TV clip 2 = moderate representation, TV clip 3 = less advantageous representation) (see Figure 1).

Since only one of the computers in the researchers' media laboratory was equipped with the remote eye-tracking tool (SensoMotoric Instruments [SMI] iView X Red, $120 \mathrm{~Hz}$ ) and the appropriate software, all participants set up individual appointments with the researchers. The eye-tracking software, controlled by the researchers, was used as a compliance check in this study, confirming that participants really watched the stimuli material. Participants' eyes fixation ${ }^{9}$ needed to remain on the screen for at least $95 \%$ of the TV clip presentation. A calibration and validation procedure before stimuli exposure ensured that participants' eyes (i.e., their fixation) were indeed focused on the stimuli (derivation x: $M=.47 ; S D=.22$; derivation $\mathrm{y}: M=.47 ; S D=.21$ ). After stimuli presentation, an on-screen post-survey questionnaire re-measured the participants' epistemological beliefs (Time Two $=\mathrm{t} 2$ ), repeating the same questions as before, but with a randomized order. The experiments took approximately 15 minutes each.

Students in this study were, on average, 24 years old $(M=24.12$; $S D=3.03)$, and almost two thirds (63\%) were female. Most of the students were in their

9 Fixation refers to the foveal attention on an object, and is perceived as the precise point of focus. Individual fixations typically have a duration of 100 to 600 milliseconds. 
second (31\%), fourth (25\%), or sixth (21\%) semester. The study fields of the students represented a wide variety of mostly humanities (16\%) and social sciences (68\%). There were no medical students among the participants. Based on a chi-square test for gender and field of study, and analyses of variance (ANOVAs, for the covariates), the EGs did not differ significantly in terms of any of these variables, indicating that groups were successfully randomized.

\subsection{Stimulus materials}

A content analysis (Kessler and Guenther, 2013; Kessler et al., 2014) was used to extract three different stimuli. The three video clips were all approximately three minutes in length and on the topic of Alzheimer's disease, ${ }^{10}$ but with respect to the four dimensions (see Hofer and Pintrich, 1997) of epistemological beliefs, they varied in their level of knowledge representation. The assumption was therefore that the clips would affect the epistemological beliefs of the participants differently. The measured content analytic variables with respect to the four epistemological dimensions were the representation of the (un)certainty of scientific findings, the way controversy is depicted, the number of sources or actors, and (un)scientific justification of the knowledge provided (for a full description, see Table 1).

Participants in EG1 $(n=21)$ watched a clip with a clear focus on science and its benefits (TV clip 1). This clip dealt with the chemical methylene blue, which might aid research on Alzheimer's disease. Ten years of research were summarized in this clip, which presented some evidence that this medication could help mice diagnosed with Alzheimer's disease. However, this clip also depicted uncertain findings and controversy. In comparison to the other two clips, this clip was classified by the content analysis as the most advantageous in its representation of knowledge.

Participants in EG2 $(n=25)$ watched a clip (TV clip 2) on a new scientific finding about the risks of developing Alzheimer's disease. Tests with mice had indicated that proteins could be external causes of the disease, making Alzheimer's disease infectious. However, this clip represented the opinions and results of only one scientist, and the finding had not been confirmed in any testing with humans. This TV clip was therefore rated as moderately advantageous in how it depicted knowledge with respect to the content analysis.

10 Research in this area contains a mixture of both well-established and developing knowledge, with many unanswered questions. Furthermore, students have some knowledge about Alzheimer's disease, but of course, they are not experts. This was therefore an ideal subject for the present investigation. 


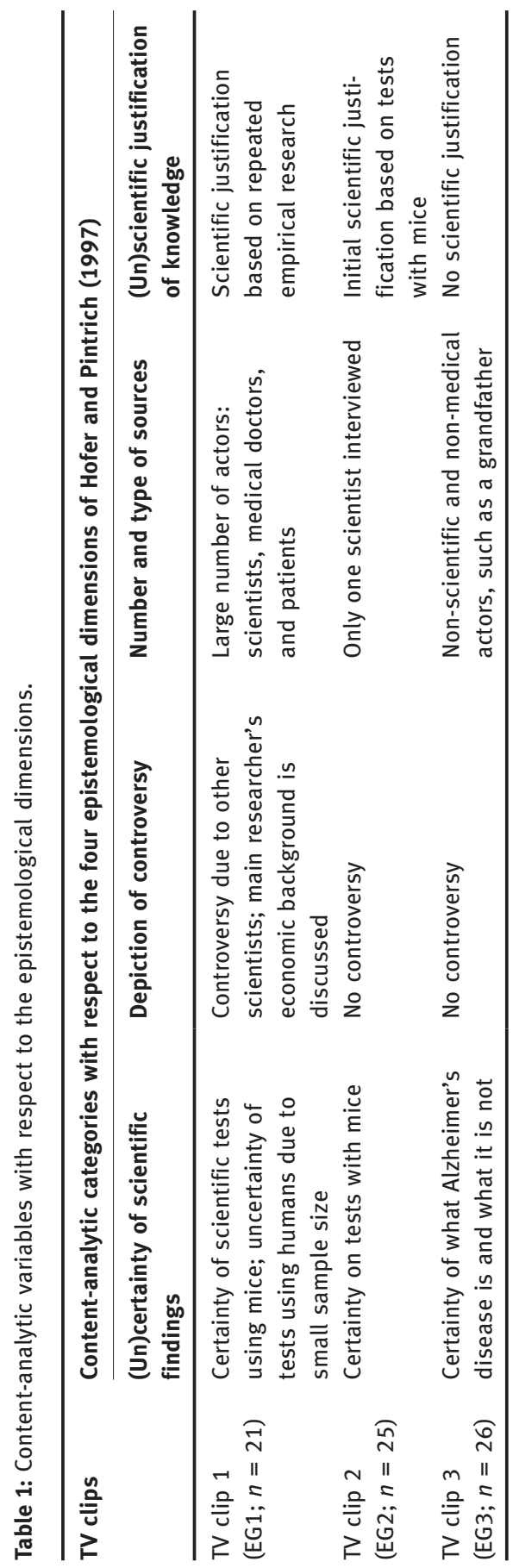


Participants in EG3 ( $n=26)$ watched a clip (TV clip 3) that offered basic information about Alzheimer's disease, with no research-related information. The clip compared how cells age naturally compared to how they age in persons with Alzheimer's disease, and this was stated as scientifically certain fact. The course of the disease was depicted in a case study, with a grandfather as the main actor. This clip was therefore classified by the content analysis as representing knowledge as less advantageous.

To ensure the successful classification of the TV clips, a manipulation check was used to test the different representations of knowledge with respect to the four epistemological dimensions (Hofer and Pintrich, 1997), also using a student sample. ${ }^{11}$ The use of real TV clips in this investigation was beneficial because it increased the external validity of the experiment.

\subsection{Measurement of variables}

Epistemological beliefs were measured specifically for medical knowledge with three items per dimension (12 items in total). Items were adapted from Urhahne and Hopf (2004), who translated and validated the questionnaire of Conley et al. (2004). We used a 6-point Likert-type scale ( $\alpha=.75$, both t1 and t2) to assess participants' degree of agreement from 1 (total disagreement) to 6 (total agreement). An example item was: "To make results more certain, it is important to perform experiments more than once”. Although a confirmatory factor analysis using principal component analysis and varimax rotation ( $\mathrm{KMO}=0.62$ ) resulted in four factors, the results did not perfectly replicate the classification proposed by Hofer and Pintrich (1997) or the one suggested by Urhahne and Hopf (2004).

11 For a manipulation check, to confirm that the chosen TV clips were accurately perceived as representing knowledge differently, 56 students $\left(M_{\text {age }}=21.79, S D_{\text {age }}=2.05,80 \%\right.$ female $)$ from Friedrich Schiller University in Jena, Germany, who were unfamiliar with the purpose of the study, were divided into three groups. Each group was then exposed to one of the identified TV clips. The participants were asked to indicate, using a 5-point Likert-type scale, how each clip represented the perceived certainty (dimension 1; $F(2 ; 52)=13.699 ; p<0.001 ; \eta^{2}=$ .34 ), controversy (dimension $2, F(2 ; 52)=13.942 ; p<0.001 ; \eta^{2}=.35$ ), number of sources (dimension 3), and justification for knowing (dimension 4, $F(2 ; 52)=3.035 ; p<0.1 ; \eta^{2}=.10$ ), as well as the comprehensibility and emotionality of the TV clips. Each media stimulus was rated by a minimum of 16 people. Analyses of variance revealed that the TV clips were perceived differently and in line with the classification of more advantageous, moderately advantageous, and less advantageous for three of the four epistemological dimensions by Hofer and Pintrich (1997). As desired, the clips were not found to differ with regard to comprehensibility or emotionality. 
The first factor (4 items) represented the source(s) of knowledge dimension (eigenvalue $=3.45$, explaining $29 \%$ of the variance). The second factor ( 4 items) was the certainty of knowledge dimension (eigenvalue $=1.68$, explaining $14 \%$ of the variance). The third factor (2 items) was the justification for knowing dimension (eigenvalue $=1.40$, explaining $12 \%$ of the variance), while the fourth factor ( 2 items) was the development of knowledge dimension (eigenvalue $=1.12$, explaining $9 \%$ of the variance).

The research literature also suggested measurement of important covariates (Kienhues et al., 2008; Sinatra et al., 2014).12 Need for cognition was measured on the same 6-point Likert-type scale $(M=25.63 ; S D=5.93 ; \alpha=.75)$ using ten items adapted from Bless, Fellhauer, Bohner, and Schwarz (1991). An example item was: "I really enjoy the task of finding new solutions to problems". The total additive index for these 10 items ranged from 0 to 60. Need for cognitive closure was measured on the same 6-point Likert-type scale $(M=49.26 ; S D=$ 9.99; $\alpha=.81$ ) using 16 items adapted from Schlink and Walther (2007). An example item - this one, reverse-coded - was: "I do not like it when the statements of persons are ambiguous". The additive index for these 16 items ranged from 0 to 96. Issue-related involvement was measured using eight 5-point semantic differentials $(M=19.69 ; S D=5.32 ; \alpha=.83)$. Items were adapted from McQuarrie and Munson (1992) and assessed perceptions of Alzheimer's disease (e.g., as interesting or important). The additive index for these eight items ranged from 0 to 40 .

On a 5-point Likert-type scale ranging from very negative (1) to very positive (5), the survey also measured how participants evaluated research on Alzheimer's disease $(M=3.81 ; S D=0.99)$. Since the present study had a clear medical focus, we asked participants about their past experiences with medicine $(M=3.56 ; S D=0.95)$, using a 5-point Likert-type scale ranging from negative (1) to positive (5) as well as their degree of interest in medical research findings $(M=3.74 ; S D=0.84)$, to which they responded on a 5-point Likerttype scale ranging from not at all (1) to very much (5). Participants were asked how often they watched clips from science TV programs, on a 5-point Likerttype scale ranging from never (1) to quite often (5). Only $10 \%$ of them watched science TV programs on a regular basis $(M=2.46$; $S D=0.93) .{ }^{13}$ They were also asked to provide sociodemographic information.

12 The role of more motivational factors when assessing a change in epistemological beliefs has been discussed in the research literature on conceptual change (Dole and Sinatra, 1998; see also Kienhues et al., 2008; Sinatra et al., 2014). Some authors also discussed the moderating role of sociodemographics (Conley et al., 2004).

13 This finding contradicts the popularity of science TV programs. This could, however, be related to the use of a student sample or to the fact that we asked for regular viewing behavior. 


\section{Results}

A more detailed look at participants' epistemological beliefs in the pre-survey questionnaire (t1) showed that the most advantageous views the students had were related to the dimensions certainty of knowledge $(M=21.85 ; S D=2.00$; range 4 to 24$)$ and development of knowledge $(M=11.22 ; S D=.93$; range 2 to $12)$, with only slightly lower values for the source(s) of knowledge $(M=18.18$; $S D=3.70$; range 4 to 24$)$ and justification for knowing dimensions $(M=9.89$; $S D=1.55$; range 2 to 12$).{ }^{14}$

Repeated-measures ANOVAs (see also Table 2) revealed differences in epistemological beliefs between the two measurement points for three of the four epistemological dimensions, answering the RQ and working towards responding to the hypotheses.

For the source(s) of knowledge dimension, a small but significant difference emerged between the two measurement points $\left(F(1 ; 67)=20.072 ; p<.001 ; \eta^{2}=\right.$ .04). Examination of the detailed comparison for each EG showed that there was no change in this epistemological dimension for the experimental condition exposed to the TV clip classified as representing knowledge as more advantageous (EG1). However, there were significant differences for the conditions in which students saw the TV clip representing knowledge as moderately advantageous $\left(\mathrm{EG} 2 ; F(1 ; 25)=17.427 ; p<.001 ; \eta^{2}=.12\right)$ and less advantageous (EG3; $\left.F(1 ; 22)=12.000 ; p<.01 ; \eta^{2}=.08\right)$. In both groups, there was a rather small

14 Regarding individual items assessing the dimension source(s) of knowledge (all items reverse-coded), the participants did not agree that there was only one solution to medical experiments $(M=1.46 ; S D=.68)$. They also did not believe that everything they read in medical books was true $(M=2.91 ; S D=1.44)$ or that they had to believe the findings of medical experts $(M=2.34 ; S D=1.20)$. Their agreement was slightly higher regarding whether only medical experts know what is true in the field of medicine $(M=3.10 ; S D=1.35)$. With respect to the dimension simplicity of knowledge (first two items reverse-coded), participants did not agree that almost everything is known in the field of medicine $(M=1.33 ; S D=.58)$ or that medical experts agree on what they see as the true facts of their field of expertise $(M=$ $1.66 ; S D=.85$ ). The students understood that there were open questions in the field of medicine that medical experts cannot yet answer $(M=5.64 ; S D=.59)$ and they agreed that there is more than one way for those in the medical field to verify beliefs $(M=5.19 ; S D=.80)$. Regarding justification for knowing, participants agreed that it is important to repeat experiments to validate findings $(M=5.54 ; S D=.84)$. Their agreement was slightly lower regarding whether experiments are a good way to reach results $(M=4.36$; $S D=.99)$. Finally, regarding the development of knowledge dimension, participants agreed that new discoveries could change what medical professionals perceive to be true $(M=5.42 ; S D=.72)$ and that more recent medicine-related beliefs may differ from past beliefs $(M=5.81 ; S D=.39)$. 
Table 2: Means of epistemological dimensions for pre- and post-survey measurement.

\begin{tabular}{|c|c|c|c|c|c|}
\hline \multirow[t]{2}{*}{ Epistemological dimensions } & \multirow[t]{2}{*}{ Groups } & \multicolumn{2}{|c|}{ Pre-survey test (t1) } & \multicolumn{2}{|c|}{ Post-survey test (t2) } \\
\hline & & $M$ & $S D$ & $M$ & $S D$ \\
\hline \multirow[t]{3}{*}{ Source(s) of knowledge } & EG1 & 16.15 & 4.17 & 16.05 & 3.36 \\
\hline & EG2 & $18.68^{\star \star \star}$ & 3.17 & $16.32^{\star \star \star}$ & 3.35 \\
\hline & EG3 & $19.45^{\star \star}$ & 3.13 & $17.63^{\star \star}$ & 3.21 \\
\hline \multirow[t]{3}{*}{ Certainty of knowledge } & EG1 & $21.60^{\star \star}$ & 2.16 & $20.65^{\star \star}$ & 2.13 \\
\hline & EG2 & $22.24^{\star \star}$ & 1.76 & $21.00^{\star \star}$ & 2.08 \\
\hline & EG3 & $21.63^{\star \star}$ & 2.15 & $20.59^{\star \star}$ & 2.26 \\
\hline \multirow[t]{3}{*}{ Justification for knowing } & EG1 & $9.75^{*}$ & 2.03 & $10.80^{\star}$ & 1.00 \\
\hline & EG2 & 10.08 & 1.38 & 10.44 & 1.00 \\
\hline & EG3 & 9.82 & 1.26 & 9.82 & 1.05 \\
\hline \multirow[t]{3}{*}{ Development of knowledge } & EG1 & 11.15 & 1.04 & 11.10 & .85 \\
\hline & EG2 & 11.20 & .82 & 11.28 & .98 \\
\hline & EG3 & 11.22 & 9.34 & 11.36 & 1.00 \\
\hline
\end{tabular}

Note: $\mathrm{EG1}=$ more advantageous representation of knowledge; $\mathrm{EG} 2=$ moderate advantageous representation, EG3 = less advantageous representation. ${ }^{* \star *}=p<.001$; ${ }^{* *}=p<.01 ;{ }^{*}=p<.05$.

decrease of means (see Table 2). This led us to the assumption that for this epistemological dimension, we gained no support for $\mathrm{H1}$, but some support for H2.

For the certainty of knowledge dimension, a small but significant difference occurred between the two measurement points as well $(F(1 ; 67)=36.738 ; p<.01$; $\left.\eta^{2}=.07\right)$. Looking at the groups we found that there was a decrease of means for this dimension for all experimental conditions: Significant and small decreases emerged (see also Table 2) for $\operatorname{EG1}\left(F(1 ; 20)=10.408 ; p<.01 ; \eta^{2}=.05\right)$, EG2 $\left(F(1 ; 25)=14.290 ; p<.01 ; \eta^{2}=.10\right)$ and $\operatorname{EG} 3\left(F(1 ; 22)=13.664 ; p<.01 ; \eta^{2}=\right.$ .06). This finding, again, gave no support for $\mathrm{H} 1$, but some for $\mathrm{H} 2$.

The small differences emerging for the justification for knowing dimension between the two measurement points $\left(F(1 ; 67)=9.516 ; p<.01 ; \eta^{2}=.03\right)$ were related - when looking at the groups individually - to a small increase of means in EG1 (more advantageous representation of knowledge $(F(1 ; 20)=$ 7.912; $p<.05 ; \eta^{2}=.10$ ), supporting H1. No differences were found for the other groups (moderate or less advantageous representation of knowledge), not supporting $\mathrm{H} 2$.

Similar tests with the development of knowledge dimension did not show significant differences either. For none of the epistemological belief dimensions was there any interference from the covariates. 


\section{Discussion}

Information about science and health is important in daily life for all societies that are highly dependent on their knowledge. Such information can have a significant influence on many everyday decisions (Bromme and Kienhues, 2014; Sinatra et al., 2014). Research in education and psychology supports the importance of fostering more advantageous epistemological beliefs among students (Conley et al., 2004; Sinatra et al., 2014; Urhahne and Hopf, 2004).

In this study, we considered whether TV clips are able to foster more advantageous epistemological beliefs among students. Television has a social role in providing education; therefore, TV clips might be able to transfer epistemological understandings (Kessler and Guenther, 2013). Although the observed differences at the two measurement points were rather small and did not fully support or reject the hypotheses, it should be highlighted that, against the background of recent research working with researcher-designed texts in mostly formal learning scenarios (Kienhues et al., 2008; Kienhues et al., 2011), the effects reported in this article are based on real-world and thus authentic material. In addition, the interventions were presented once only and they were each just about three minutes in length. While these were only short interventions, they were still realistic since German science TV program clips are designed this way (Milde, 2009).

Students who watched a TV clip depicting knowledge of Alzheimer's disease as more advantageous did not appear to change their epistemological beliefs. A small effect only was observed for the justification for knowing dimension. Students in this group were also among the participants perceiving medical knowledge after exposure as slightly more certain than before, a finding contrary to what was expected. Regarding the conceptual change literature, there is a chance that the chosen TV clip for this group, although being classified as a more advantageous representation of knowledge, was not able to lead to cognitive discrepancies and dissonance; thus, also not to conceptual change. Although discussing both certain and uncertain research findings, certain findings might have been more dominant and important for certain viewers, leading to this finding. On the other hand, this clip introduced a large number of varying actors discussing various standpoints, which could have led to a weak change in the justification for knowing dimension. Overall, since participants, in general, already had more advantageous epistemological beliefs before exposure, the TV clip might just have confirmed what they already knew.

In contrast, in two dimensions (source(s) of knowledge and certainty of knowledge) we found some partial support for the assumption that TV clips depicting knowledge as moderately advantageous or less advantageous lead to 
a decrease in epistemological beliefs among the students. This is to some degree in line with current research (Kienhues et al., 2008). The finding was also hypothesized. Results could have been based on the fact that both clips showed one actor only and represented knowledge as rather certain.

In sum, the present study did not offer a clear answer on whether or not the representation of knowledge in TV clips can change students' epistemological beliefs into more or less advantageous ones. Since this study - to the authors' knowledge - is the first one exploring changes of epistemological beliefs caused by audio-visual stimuli (i.e., TV clips), it can be a starting point for interesting approaches in this relevant field of research.

This study had a number of notable limitations, necessitating more research in this field. The use of a small sample comprising university students only was of course not representative and might have resulted in overall highly advantageous epistemological beliefs before exposure to stimuli. If the sample had contained younger students, probably with less advantageous epistemological beliefs before experimental exposure, the TV clip classified as representing more advantageous knowledge might have had a more significant effect. It is therefore important to repeat this experiment with different samples. It should also be highlighted that, although this experiment was aimed at having a successful randomization of participants in the EGs, as can be seen in Table 2, the students had different starting points in the source(s) of knowledge dimension of epistemological beliefs. This might have affected the results as well, requiring further replication of the experiment.

In addition, the study methodology did not allow the researchers to determine whether the measured effects were short or long term. An experimental design repeating the survey at different points in time would allow this additional information to be gathered. Furthermore, the time difference between measurements before and after the research might be of concern. We suggest that future research allows more time to pass before repeating the research in order to measure epistemological beliefs. There was also no measurement of prior knowledge about the subject as a potential covariate (Bråten et al., 2011; Kienhues et al., 2008) in this investigation. This should be included in future research. Using eye-tracking as a compliance check might have benefits, but could be extended (e.g., by surveying what participants remember about the clip after exposure).

The TV clips were specific to Alzheimer's disease and there were differences in how they portrayed the subject. While clip 1 was related to the treatment of the disease, the other two clips focused on the development and causes of the disease. By using a more extended sample for content analysis, this important limitation might be avoided. The content analysis used for this investigation 
also did not measure whether the pictures as presented in the clips contained different levels of epistemological image. The authors of this study, therefore, hope that other researchers will include the degree of epistemology presented in pictures into their future analyses.

Epistemological beliefs that were measured in this study were domain-specific and therefore strictly related to the area of medicine. The results can therefore not be generalized. In addition, participants were in a laboratory to take part in the experiment. While we think that this was reasonable keeping in mind that the eye-tracking ensured that the presented TV clips were watched by the students, we encourage other researchers to repeat this experiment in different settings.

Lastly, there have been calls for mixed-methods approaches. The present study could be supplemented by - for instance - thinking-aloud methodologies (Ferguson et al., 2012) or qualitative interviews (Greene and Yu, 2014). It would also be interesting to repeat this investigation in a classroom scenario in which the lecturer discusses the content of the TV clips with the students (as in Broughton et al., 2013), for example, also after exposure to multiple clips that depict knowledge very differently (Ferguson et al., 2012). In these investigations, underlying mechanisms of change (Rule and Bendixen, 2010) might also be understood better. This is highly important since, in current knowledge societies, more advantageous epistemological beliefs are believed to function as a lens through which individuals absorb new information, and these beliefs are therefore crucial for information reception processes.

\section{References}

Ashe, T. 2013. How the media report scientific risk and uncertainty: A review of the literature. Oxford: Reuters Institute for the Study of Journalism.

Bendixen, L. D., \& Rule, D. C. 2004. An integrative approach to personal epistemology: A guiding model. Educational Psychologist 39(1). 69-80. doi:10.1207/ s15326985ep3901_7

Bless, H., Fellhauer, R. F., Bohner, G., \& Schwarz, N. 1991. Need for cognition: Eine Skala zur Erfassung von Engagement und Freude bei Denkaufgaben [Need for cognition: A scale measuring commitment and joy in thinking tasks]. ZUMA-Arbeitsbericht 91(6). $1-12$.

Bråten, I., Britt, M. A., Strømsø, H. I., \& Rouet, J.-F. 2011. The role of epistemic beliefs in the comprehension of multiple expository texts: Towards an integrated model. Educational Psychologist 46. 48-70. doi:10.1080/00461520.2011.538647

Bromme, R., \& Kienhues, D. 2014. Wissenschaftsverständnis und Wissenschaftskommunikation [Understanding science and science communication]. 
In T. Seidel \& A. Krapp (Eds.), Pädagogische Psychologie [Pedagogical psychology] (pp. 55-81). Weinheim: Beltz Psychologie Verlags Union.

Broughton, S. H., Sinatra, G. M., \& Nussbaum, E. M. 2013. "Pluto has been a planet my whole life!" Emotions, attitudes, and conceptual change in elementary students learning about Pluto's reclassification. Research in Science Education 43. 529-550. doi:10.1007/s11165-011-9274-x

Chinn, C. A., Buckland, L. A., \& Samarapungavan, A. 2011. Expanding the dimensions of epistemic cognition: Arguments from philosophy and psychology. Educational Psychologist 46. 141-167. doi:10.1080/00461520.2011.587722

Conley, A. M., Pintrich, P. R., Vekiri, I., \& Harrison, D. 2004. Changes in epistemological beliefs in elementary science students. Contemporary Educational Psychology 29(2). 186-204. doi:10.1016/j.cedpsych.2004.01.004

Dole, J. A., \& Sinatra, G. M. 1998. Reconceptualizing change in the cognitive construction of knowledge. Educational Psychologist 33(2/3). 109-128. doi:10.1080/ 00461520.1998 .9653294

European Commission. 2013. Responsible research and innovation (RRI), science and technology. Report on Special Eurobarometer 401. Retrieved February 6, 2015 from http://ec.europa.eu/public_opinion/archives/ebs/ebs_401_en.pdf.

Ferguson, L. E., Bråten, I., \& Strømsø, H. I. 2012. Epistemic cognition when students read multiple documents containing conflicting scientific evidence: A think-aloud study. Learning and Instruction 22. 103-120. doi:10.1016/j.learninstruc.2011.08.002

Gill, M. G., Ashton, P. T., \& Algina, J. 2004. Changing preservice teachers' epistemological beliefs about teaching and learning in mathematics: An intervention study. Contemporary Educational Psychology 29. 164-185. doi:10.1016/ j.cedpsych.2004.01.003

Greene, J. A., \& Yu, S. B. 2014. Modeling and measuring epistemic cognition: A qualitative re-investigation. Contemporary Educational Psychologist 39. 12-28. doi:10.1016/ j.cedpsych.2013.10.002

Hofer, B. K. 2001. Personal epistemology research: Implications for learning and transfer. Educational Psychology Review 13. 353-383.

Hofer, B. K. 2004a. Exploring the dimensions of personal epistemology in differing classroom contexts: Students' interpretations during the first year of college. Contemporary Educational Psychology 29. 129-163. doi:10.1016/ j.cedpsych.2004.01.002

Hofer, B. K. 2004b. Epistemological understanding as a metacognitive process: Thinking aloud during online searching. Educational Psychologist 39(1). 43-55. doi:10.1207/ s15326985ep3901_5

Hofer, B. K. 2010. Personal epistemology in Asia: Burgeoning research and future directions. The Asia-Pacific Education Researcher 19(1). 179-184. doi:10.3860/taper.v19i1.1516

Hofer, B. K., \& Pintrich, P. R. 1997. The development of epistemological theories: Beliefs about knowledge and knowing and their relation to learning. Revue of Educational Research 67. 88-140. doi:10.3102/00346543067001088

Jacobson, M. J., \& Spiro, R. J. 1995. Hypertext learning environments, cognitive flexibility, and the transfer of complex knowledge: An empirical investigation. Journal of Educational Computing Research 12(4). 301-333. doi:10.2190/4T1B-HBP0-3F7E-J4PN

Kessler, S.H., \& Guenther, L. 2013. Depicted epistemological dimensions in science coverage: How science television programs represent knowledge of molecular 
medicine. Journal of International Scientific Publications, Media and Mass

Communication 2. 272-290.

Kessler, S.H., \& Guenther, L. 2017. Eyes on the frame: Explaining people's online searching behavior in response to TV consumption. Internet Research 27(2). doi:10.1108/IntR-012016-0015.

Kessler, S.H., Guenther, L., \& Ruhrmann, G. 2014. Die Darstellung epistemologischer Dimensionen von evidenzbasiertem Wissen in TV-Wissenschaftsmagazinen. Ein Lehrstück für die Bildungsforschung [The representation of epistemological dimensions of evidence-based knowledge in science TV programs. A lesson for educational research.]. Zeitschrift für Erziehungswissenschaft 17(4). 119-139. doi: 10.1007/s11618014-0512-7

Kienhues, D., Bromme, R., \& Stahl, E. 2008. Changing epistemological beliefs: The unexpected impact of a short-term intervention. British Journal of Educational Psychology 78. 545-565. doi:10.1348/000709907X268589

Kienhues, D., Ferguson, L. E., \& Stahl, E. 2016. Diverging information and epistemic change. In J. Greene, W. Sandoval, \& I. Braten (Eds.), Handbook of epistemic cognition (pp. 318330). New York, NY: Routledge.

Kienhues, D., Stadtler, M., \& Bromme, R. 2011. Dealing with conflicting or consistent medical information on the Web: When expert information breeds laypersons' doubts about experts. Learning and Instruction 21. 193-204. doi:10.1016/ j.learninstruc.2010.02.004

King, P. M., \& Kitchener, K. S. 2002. The reflective judgment model: Twenty years of research on epistemic cognition. In B. K. Hofer \& P. R. Pintrich (Eds.), Personal epistemology: The psychology of beliefs about knowledge and knowing (pp. 37-61). Mahwah, NJ: Lawrence Erlbaum.

Kuhn, D., Cheney, R., \& Weinstock, M. 2000. The development of epistemological understanding. Cognitive Development 15. 309-328.

Lehmkuhl, M., Karamanidou, C., Mörä, T., Petkova, K., Trench, B., \& AVSA-Team 2012. Scheduling science on television: A comparative analysis of the representations of science in 11 European countries. Public Understanding of Science 21. 1002-1018. doi:10.1177/0963662511436070

Lombardi, D., Sinatra, G. M., \& Nussbaum, E. M. 2013. Plausibility reappraisals and shifts in middle school students' climate change conceptions. Learning and Instruction 27. 5062. doi:10.1016/j.learninstruc.2013.03.001

Louca, L., Elby, A., Hammer, D., \& Kagey, T. 2004. Epistemological resources: Applying a new epistemological framework to science instruction. Educational Psychologist 39(1). 57-68. doi:10.1207/s15326985ep3901_6

McQuarrie, E. F., \& Munson, J. M. 1992. A revised product involvement inventory: Improved usability and validity. NA - Advances in Consumer Research 19. 108-115.

Milde, J. 2009. Vermitteln und verstehen: Zur Verständlichkeit von Wissenschaftsfilmen im Fernsehen [Mediation and understanding: About the comprehensibility of science films on television]. Wiesbaden: VS.

Muis, K. R., \& Duffy, M. C. 2013. Epistemic climate and epistemic change: Instruction designed to change students' beliefs and learning strategies and improve achievement. Journal of Educational Psychology 105(1). 213-225. doi:10.1037/a0029690

Mumtaz, S. 2006. Factors affecting teachers' use of information and communications technology: A review of the literature. Journal of Information Technology for Teacher Education 9(3). 319-342. doi:10.1080/14759390000200096 
Popper, K. 1960. The logic of scientific discovery. London: Hutchinson \& Co.

Rule, D. C., \& Bendixen, L. D. 2010. The integrative model of personal epistemology development: Theoretical underpinnings and implications for education. In L. D. Bendixen \& F. C. Feucht (Eds.), Personal epistemology in the classroom (pp. 94-123). Cambridge: Cambridge University Press.

Schlink, S., \& Walther, E. 2007. Kurz und gut: Eine deutsche Kurzskala zur Erfassung des Bedürfnisses nach kognitiver Geschlossenheit [Short and sweet: A German short scale to measure need for cognitive closure]. Zeitschrift für Sozialpsychologie 38. 153-161. doi:10.1024/0044-3514.38.3.153

Schommer, M. 1990. Effects of beliefs about the nature of knowledge on comprehension. Journal of Educational Psychology 82(3). 498-504. doi:10.1037/0022-0663.82.3.498

Schommer-Aikins, M. 2004. Explaining the epistemological belief system: Introducing the embedded systemic model and coordinated research approach. Educational Psychologist 39(1). 19-29. doi:10.1207/s15326985ep3901_3

Sinatra, G. M., Kienhues, D., \& Hofer, B. K. 2014. Addressing challenges to public understanding of science: Epistemic cognition, motivated reasoning, and conceptual change. Educational Psychologist 49(2). 123-138. doi:10.1080/00461520. 2014.916216

Urhahne, D., \& Hopf, M. 2004. Epistemologische Überzeugungen in den Naturwissenschaften und ihre Zusammenhänge mit Motivation, Selbstkonzept und Lernstrategien [Epistemological beliefs in the natural sciences and their relationships with motivation, self-concept, and learning strategies]. Zeitschrift für Naturwissenschaften 10. 70-86.

Wegner, C., Weber, P., \& Fischer, O. S. 2012. Epistemologische Überzeugungen: Eine Untersuchung zur Beeinflussbarkeit der Auffassung über die Natur des Wissens [Epistemological beliefs: A study on the controllability of views about the nature of knowledge]. news\&science. Begabtenförderung und Begabungsforschung 30(1). 49-56. 